\title{
Sistem Pengendali Otomatis Debit Air pada Simulasi Bendungan Menggunakan Mikrokontroler ATMEGA 32 dan Komunikasi Serial
}

\author{
Zulfachmi $^{1}$, Wanhendra ${ }^{2}$, Danandjaya Saputra ${ }^{3 *}$ \\ 1,2,3 Jurusan Teknik Informatika STT Indonesia Tanjungpinang \\ Jln. Pompa Air No. 28 Tanjungpinang Kepulauan Riau Indonesia \\ ${ }^{1}$ fahmi.stti@gmail.com \\ ${ }^{2}$ wanhendra@sttindonesia.ac.id \\ 33anandj@gmail.com
}

\begin{abstract}
Intisari- Bendungan adalah konstruksi yang dibangun untuk menahan laju air menjadi waduk, danau, atau tempat rekreasi. Seringkali bendungan juga digunakan untuk mengalirkan air ke sebuah Pembangkit Listrik Tenaga Air. Kebanyakan bendungan juga memiliki bagian yang disebut pintu gerbang air untuk membuang air yang tidak diinginkan secara bertahap atau berkelanjutan. Berdasarkan permasalahan yang ada, penulis melakukan analisa dan merancang sistem baru yang mengantisipasi kelemahan-kelemahan pada sistem yang berjalan tanpa menimbulkan permasalahan-permasalahan baru. Sistem pengendali otomatis debit air pada simulasi bendungan menggunakan mikrokontroler atmega 32 dan komunikasi serial yang penulis usulkan telah menjawab permasalahan yang timbul. Sistem pengendali otomatis debit air pada simulasi bendungan menggunakan mikrokontroler atmega 32 dan komunikasi serial dapat memberikan hasil yang baik dalam memberikan data level ketinggian air pada wadah akuarium yang diujikan. Software yang digunakan sebagai alat bantu dalam penelitian ini adalah Borland Delphi7 dan Arduino serta metodologi yang digunakan untuk perkembangan aplikasi ini adalah metode Spiral. Hasil pengembangan dari sistem ini diharapkan dapat memberikan kemudahan pemerintah dalam membenahi saluran air.
\end{abstract}

Kata kunci- Arduino, Bendungan, Debit Air, Mikrokontroler, Pembangkit Listrik Tenaga Air.

Abstract - Dam is a construction that is built to restrain rate of water into a reservoir, lake, or recreation area. Often dams are also used to drain water to a hydroelectric power plant. Most dams also have a section called the water gate to remove unwanted water gradually or continuously. Based on the existing problems, the author analyzes and designs a new system that anticipates weaknesses in the running system without causing new problems. The automatic control system for water discharge in the dam simulation uses the ATMEGA 32 microcontroller and the serial communication that the author proposes has answered the problems that arise. The automatic control system for water discharge in the dam simulation using the ATMEGA 32 microcontroller and serial communication can give good results in providing water level data in the aquarium container tested. The software used as a tool in this research is Borland Delphi7 and Arduino and the methodology used for the development of this application is the Spiral method. The results of the development of this system are expected to make it easier for the government to fix waterways. Keywords - Arduino, Dam, Hydro Power Plant, Microcontroller, Water Discharge.

\section{Pendahuluan}

Sistem pengendali otomatis merupakan penerapan dari salah satu sistem robotika. Di bidang ilmu pengetahuan dan teknologi saat ini sistem pengendali otomatis berkembang dengan sangat pesat. Dengan adanya perkembangan teknologi, pekerjaan yang semulanya dikerjakan oleh fisik manusia secara keseluruhan dapat dikerjakan secara otomatis dengan penerapan sistem robotika sehingga pekerjaan lebih mudah terkontrol dan efektif[1]. Penerapan dan pengembangan sistem robotika yang dihubungkan dengan alat-alat elektronik membuat sebuah kemajuan besar didunia industri[2].

Penggunaan sistem pengendali otomatis semakin banyak ditemui baik dalam bidang industri maupun dalam kehidupan sehari-hari. Hampir diseluruh kegiatan manusia saat ini dikendalikan secara otomatis, misalnya saja dalam pengaturan waktu didalam mesin cuci, AC (Air Conditioner), maupun televisi. Ini membuktikan bahwa dalam kehidupan sehari-hari kehidupan manusia sangat bergantung kepada penggunaan elektronik yang bisa dikendalikan secara otomatis[3].

Dengan mendatangkan banyak manfaat dari kinerja sistem pengendali otomatis, banyak pabrik-pabrik industri dalam mengolah pekerjaan mereka menggunakan sistem pengendali otomatis sehingga tidak perlu membutuhkan banyak tenaga manusia dalam melakukan pekerjaan tersebut. Tidak ubahnya penggunaan sistem pengendali otomatis yang terdapat pada sebuah bendungan[4]. Bendungan air merupakan kontruksi yang dibangun untuk menahan laju air. Bendungan air memiliki pintu kanal air yang berfungsi sebagai pembuka dan penutup untuk mengalirkan maupun menahan aliran air[5]. Ketika debit air berada diatas standar kapasitas bendungan, maka pintu kanal akan terbuka. Sedangkan debit air berada dibawah standar pintu kanal akan tertutup. Turun naiknya debit air tidak dapat diperkirakan secara akurat, sehingga harus ada pengontrol untuk mengontrol ketinggian debit air[6]. Untuk mengatasi kesalahan manusia dalam pengontrolan 
tersebut perlu adanya sistem secara otomatis yang mengatur kanal air.[7]

\section{Metodologi Penelitian}

\section{A. Gambaran Umum Sistem}

Gambaran umum sistem merupakan penjelasan secara umum tentang bagaimana sistem pengendali debit air secara otomatis melakukan cara kerjanya[8]. Gambaran umum sistem dapat dilihat pada Gambar 1.

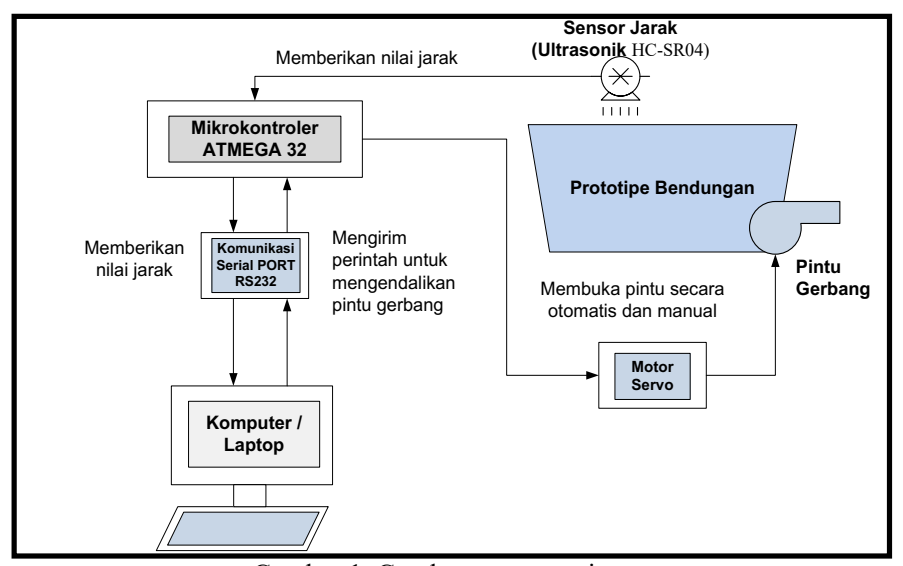

B. Perancangan Sistem

Perancangan sistem pendendali otomatis debit air pada simulasi bendungan menggunakan mikrokontroler ATMEGA 32 dan komunikasi serial dapat dilihat pada Gambar 2[9].

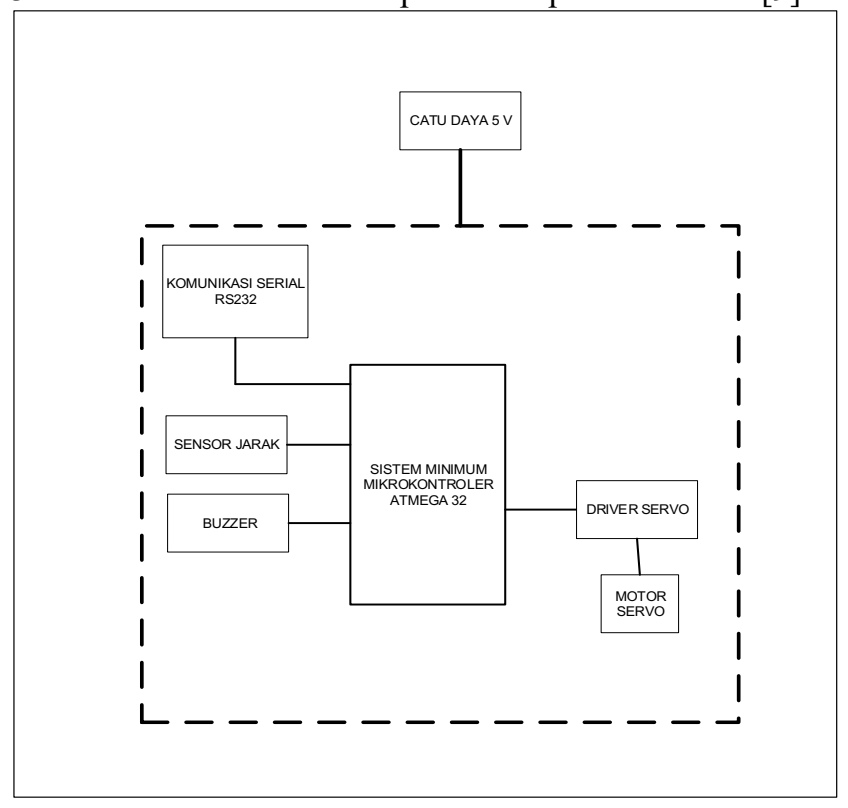

Gambar 2. Diagram Blok Sistem Pengendali Debit Air Otomatis.

Berdasarkan diagram blok sistem pengendali debit air, sistem ini terdiri dari berbagai perangkat yaitu mikrokontroler ATMEGA 32, buzzer, sensor jarak, driver servo, motor servo, komunikasi serial RS232. Adapun fungsi-fungsi dari perangkat tersebut adalah sebagai berikut :

1. Sensor Jarak

Sensor jarak berfungsi sebagai peralatan input untuk mendeteksi ketinggian level air pada akuarium.

\section{Buzzer}

Buzzer berfungsi sebagai peralatan output untuk indikator yang menggunakan suara beep ketika terjadi tanda bahaya.

3. Driver Servo

Driver servo berfungsi sebagai peralatan output untuk mengendalikan 2 motor servo kiri dan kanan. Driver motor yang digunakan SPC Servo Motor Controller.

4. Motor Servo

Servo berfungsi sebagai peralatan output untuk mengangkat pintu gerbang air. Servo yang digunakan adalah Hitec HS-311 HD.

C. Penggunaan Pin Konfigurasi pada Papan Mikrokontroler

Mikrokontroler ATmega 32 memiliki PORT yang terdiri dari pin-pin untuk menghubungkan peralatan input dan output atau disebut dengan interfacing I/O. Rangkaian I/O dari mikrokontroler mempunyai kontrol direksi yang tiap bitnya dapat dikonfigurasikan secara individual, maka dalam pengkonfigurasian I/O yang digunakan ada yang berupa operasi port ada pula yang dikonfigurasi tiap bit I/O. Simulasi pin konfigurasi dapat dilihat pada Gambar 3 dan Tabel I. [10]

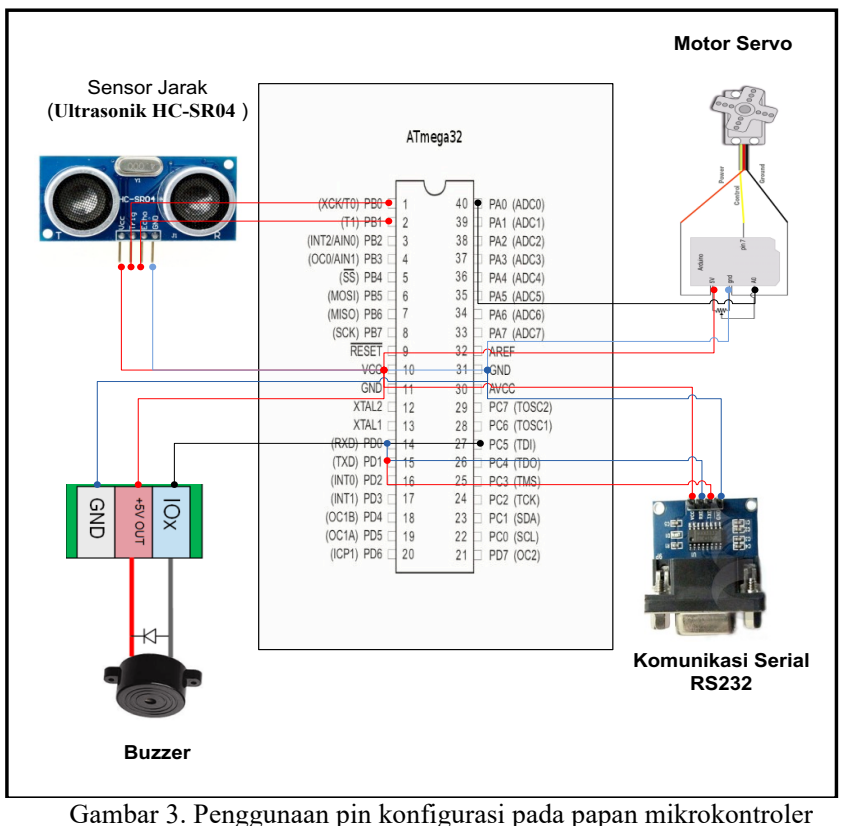

TABEL I

PIN KONFIGURASI PADA ATMEGA 32

\begin{tabular}{clcc}
\hline No. & \multicolumn{1}{c}{ Peralatan } & Interfacing & Pin \\
\hline 1. & Sensor Jarak & Input & B0,B1 \\
\hline 2. & Buzzer & Output & C5 \\
\hline 3. & Komunikasi Serial RS232 & Output & C1,C2,C3,C4 \\
\hline 4. & Motor Servo & Output & A0,A1 \\
\hline
\end{tabular}

D. Perancangan Mekanik Sistem Pengendali Debit Air

Proses perancangan mekanik meliputi proses bentuk dan material penyusun sistem pengendali debit yang berupa sebuah prototipe akuarium. Prototipe ini merupakan simulasi sebuah bendungan, yang dimana prototipe tersebut memiliki pintu-pintu gerbang air yang didesain seperti bendungan. $\mathrm{P}$ rototipe ini terbuat dari kaca dengan ukuran ketebalannya 5 mm. Selain itu akuarium ini akan diletakkan berbagai komponen seperti mikrokontroler, servo, serta sensor jarak 
sebagai alat pengendali otomatis yang akan disimulasikan. Dan juga pintu-pintu gerbang air yang berfungsi sebagai penyalur air ke wadah penampungan[11]. Ukuran dimensi dari prototipe ini disajikan pada Tabel II.

TABEL II

Dimensi PrototiPe Sistem PENGENDALI DEBIT AIR

\begin{tabular}{clc}
\hline No & \multicolumn{1}{c}{ Jenis } & Ukuran \\
\hline $\mathbf{1}$ & Panjang & $30 \mathrm{~cm}$ \\
\hline $\mathbf{2}$ & Lebar & $30 \mathrm{~cm}$ \\
\hline $\mathbf{3}$ & Tinggi & $20 \mathrm{~cm}$ \\
\hline
\end{tabular}

E. Perancangan Perangkat Lunak Sistem Pengendali Debit Air

Perancangan perangkat lunak merupakan penggambaran dari algoritma sistem pengendali otomatis. Perancangan perangkat lunak ini juga merupakan alur program yang di terapkan ke sistem pengendali otomatis, perancangan perangkat lunak ini digambarkan menggunakan flowchart. Alur sistem secara keseluruhan disajikan pada Gambar 4.

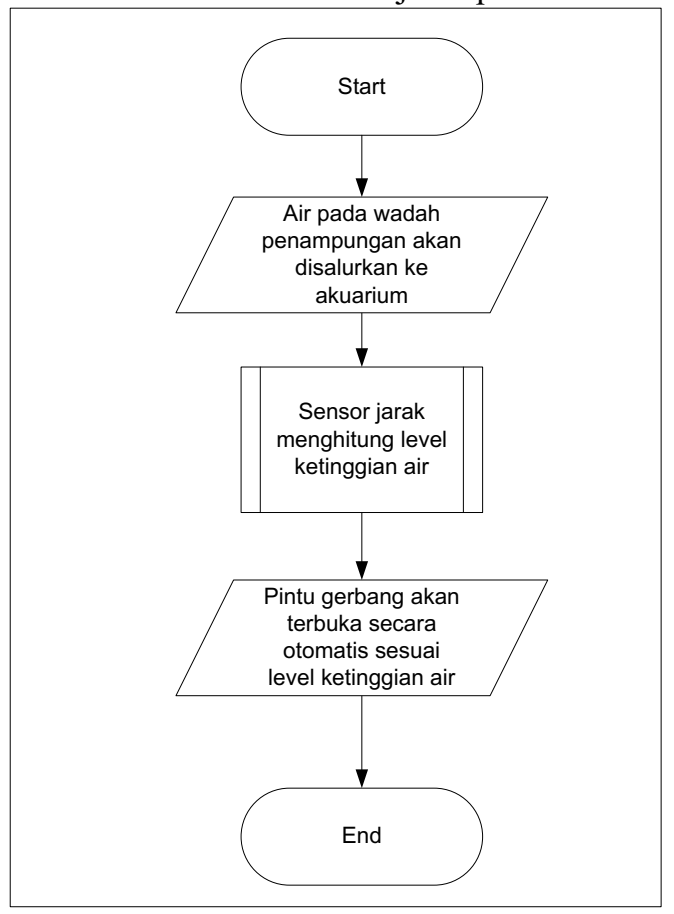

Gambar 4. Diagram alur sistem secara keseluruhan

Berdasarkan Gambar 4, air pada wadah penampungan disalurkan menuju prototipe akuarium kemudian sensor jarak pada akuarium akan menghitung level ketinggian air. Level ketinggian air pada akuarium akan berdampak pada buka tutupnya pintu gebang. Jika ketinggian air mencapai $5 \mathrm{~cm}$ maka akan terbuka satu pintu gerbang dan jika ketinggian air sudah mencapai $10 \mathrm{~cm}$ atau lebih maka terbuka dua pintu gerbang secara otomatis. Jika ketinggian air kurang dari level tersebut maka pintu akan otomatis tertutup. Diagram alur membuka pintu gerbang disajikan pada Gambar 5.

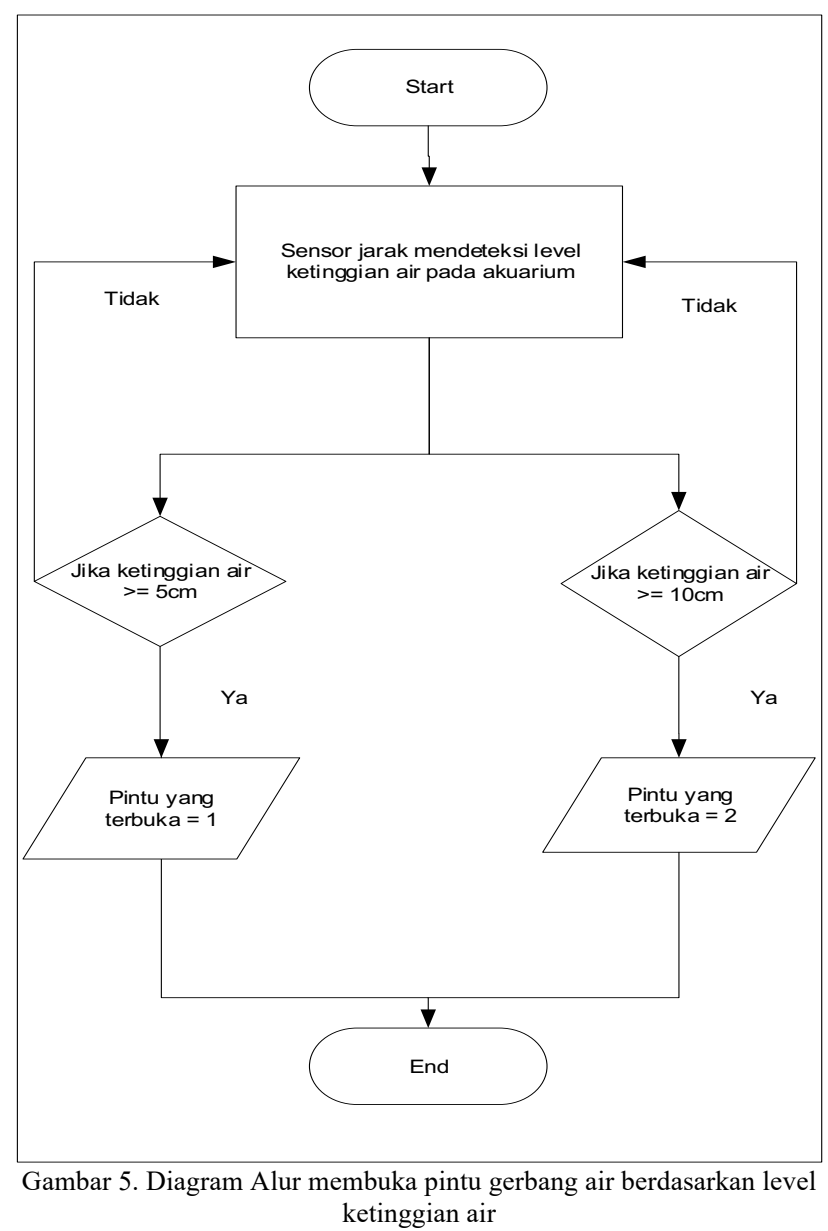

Selain itu, pada sistem pengendali debit air otomatis ini terdapat peringatan jika level ketinggian air sudah mencapai batas. Adapun flowchart tanda peringatan disajikan pada Gambar 6.

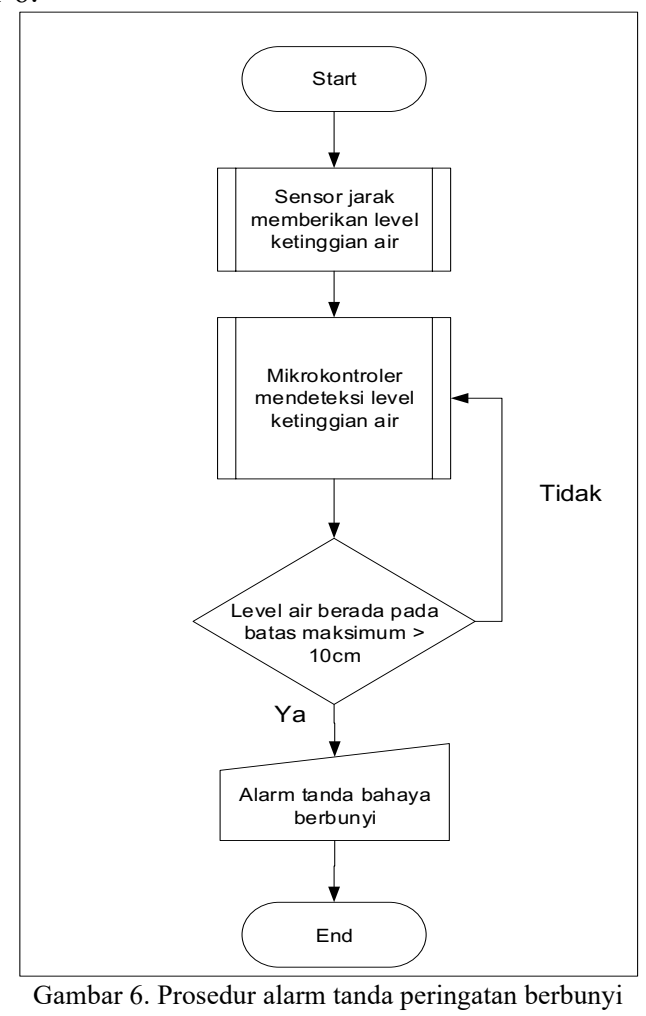


Sistem pengendali debit air otomatis ini menggunakan program borland delphi 7 dalam pengaplikasiannya. Sistem yang dirancang untuk mengetahui level debit air pada akuarium. Sistem pengendali debit air otomatis ini juga dirancang sebagai otomatis dan manual untuk membuka dan menutup pintu gerbang air. Jika pintu tidak dapat bekerja secara otomatis terdapat juga tombol untuk membuka maupun menutup pintu secara manual. Selain itu terdapat juga laporan yang menandakan bahwa saat ini level ketinggian air berada pada status aman, siaga, maupun bahaya. Sistem pengendali level debit air dapat dilihat pada Gambar 7 dan 8 .

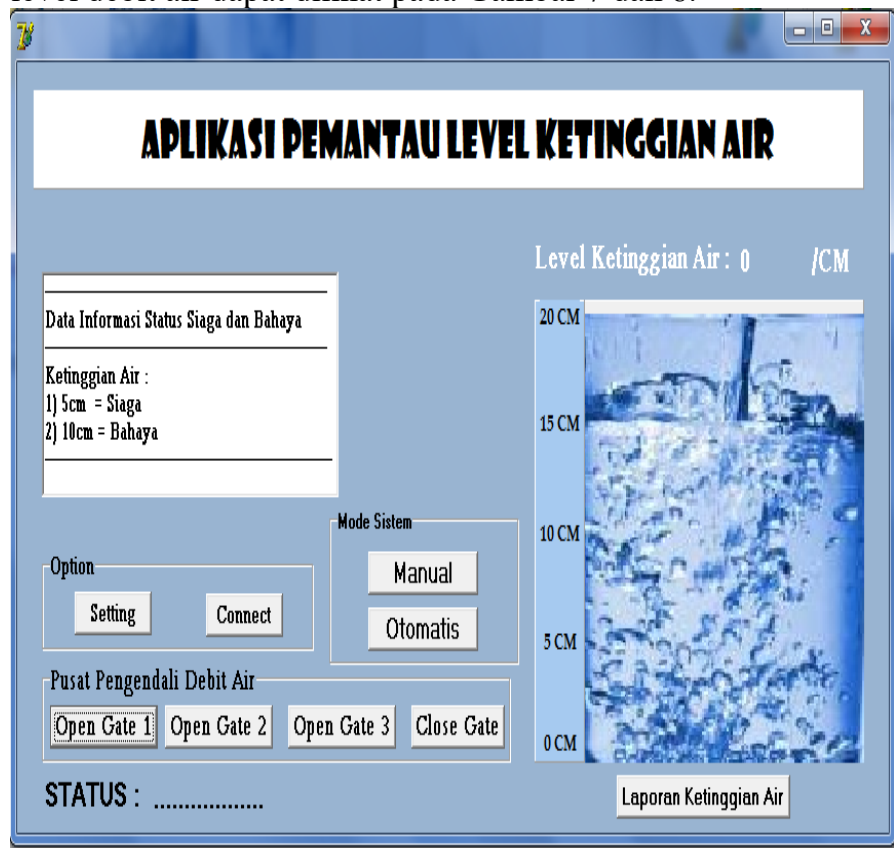

Gambar 7. Tampilan sistem pengendali debit air

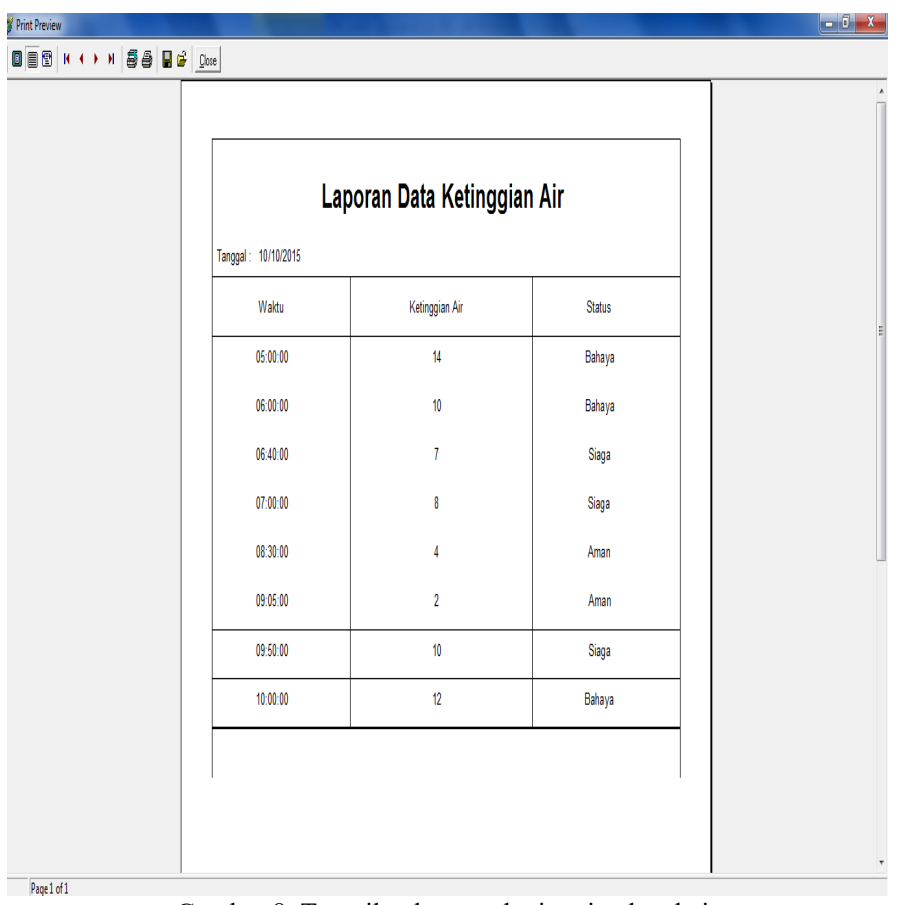

Gambar 8. Tampilan laporan ketinggian level air

\section{HASIL DAN PEMBAHASAN}

Pengujian sistem pengendali otomatis debit air pada simulasi bendungan menggunakan mikrokontroler atmega 32 dan komunikasi serial dilakukan untuk menguji keberhasilan program dan algoritma yang dirancang dengan melihat respon sistem ketika mendeteksi level ketinggian air.

TABEL III

Pengujian Sistem Pengendali Debit Air Otomatis

\begin{tabular}{ccccc}
\hline $\begin{array}{c}\text { Pengujian } \\
\text { Ke- }\end{array}$ & $\begin{array}{c}\text { Ketinggian } \\
\text { Air }(\mathbf{c m})\end{array}$ & $\begin{array}{c}\text { Pintu } \\
\text { Terbuka }\end{array}$ & Buzzer & Keterangan \\
\hline $\mathbf{1}$ & 7 & 1 & Tidak Berbunyi & Berhasil \\
\hline $\mathbf{2}$ & 13 & 2 & Berbunyi & Berhasil \\
\hline $\mathbf{3}$ & 18 & 2 & Berbunyi & Berhasil \\
\hline $\mathbf{4}$ & 8 & 1 & Tidak Berbunyi & Berhasil \\
\hline $\mathbf{5}$ & 11 & 2 & Berbunyi & Berhasil \\
\hline $\mathbf{6}$ & 6 & 1 & Tidak Berbunyi & Berhasil \\
\hline $\mathbf{7}$ & 2 & - & Tidak Berbunyi & Berhasil \\
\hline $\mathbf{8}$ & 16 & 2 & Berbunyi & Berhasil \\
\hline $\mathbf{9}$ & 4 & - & Tidak Berbunyi & Berhasil \\
\hline $\mathbf{1 0}$ & 12 & 2 & Berbunyi & Berhasil \\
\hline
\end{tabular}

Berdasarkan Tabel III dapat disimpulkan bahwa secara keseluruhan sistem pengendali debit air otomatis bekerja dengan sangat baik dengan tingkat keberhasilan sebesar $100 \%$. Sensor ultrasonik berhasil membaca ketinggian air dengan baik sehingga motor servo yang digunakan untuk membuka dan menutup pintu gerbang air dapat bekerja dengan baik.

TABEL IV

STATUS LEVEL KETINGGIAN DEBIT AIR

\begin{tabular}{ccc}
\hline $\begin{array}{c}\text { Pengujian } \\
\text { Ke- }\end{array}$ & $\begin{array}{c}\text { Kasus dan Hasil Uji } \\
\text { Air }(\mathbf{c m})\end{array}$ & Keterangan \\
\hline $\mathbf{1}$ & 7 & Siaga \\
\hline $\mathbf{2}$ & 13 & Bahaya \\
\hline $\mathbf{3}$ & 18 & Bahaya \\
\hline $\mathbf{4}$ & 8 & Siaga \\
\hline $\mathbf{5}$ & 11 & Bahaya \\
\hline $\mathbf{6}$ & 6 & Siaga \\
\hline $\mathbf{7}$ & 2 & Aman \\
\hline $\mathbf{8}$ & 16 & Bahaya \\
\hline $\mathbf{9}$ & 4 & Aman \\
\hline $\mathbf{1 0}$ & 12 & Bahaya \\
\hline
\end{tabular}

Berdasarkan Tabel IV dapat disimpulkan bahwa sistem pengendali debit air otomatis berhasil mengirimkan status dari level ketinggian air. Jika kondisi level air dibawah $5 \mathrm{~cm}$ maka status yang dihasilkan ialah aman, jika kondisi level air berada diantara $5 \mathrm{~cm}$ sampai $10 \mathrm{~cm}$ maka status yang ditampilkan adalah siaga, jika level ketinggian air berada diatas $10 \mathrm{~cm}$ maka status yang ditampilkan adalah bahaya.

\section{KESIMPULAN}

Berdasarkan hasil pengujian yang dilakukan terhadap sistem pengendali debit air otomatis tingkat keberhasilan $100 \%$. Serta sistem pengendali level air ini dapat memberikan informasi yang akurat akan level ketinggian air pada akuarium.

\section{UCAPAN TERIMA KASIH}

Penulis mengucapkan terimakasih yang sebesar-besarnya kepada STT Indonesia Tanjungpinang yang telah memberikan fasilitas dan tempat bagi penulis dalam melaksanakan 
penilitian. Mudah-mudahan penelitian ini bisa bermanfaat [6] bagi kita semua.

\section{REFERENSI}

[1] T. Complete, Robot Operating System - The Complete Reference (Volume 4), vol. 4, no. Volume 4. 2019.

[2] A. Jalil, "Pemanfaatan Middleware Robot Operating System (ROS) Dalam Menjawab Tantangan Revolusi Industri 4.0," vol. 11, no. 28 , pp. 45-52, 2019.

[3] M. Rosmiati, M. F. Rizal, F. Susanti, and G. F. Alfisyahrin, “Air pollution monitoring system using LoRa modul as transceiver system," TELKOMNIKA, vol. 17, no. 2, pp. 586-592, 2019.

[4] G. G. Maulana, S. Pancono, and A. Mia, "Desain dan Implementasi Sistem Pengendalian Otomatis untuk Mengatur Debit Air Pada Prototipe Bendung sebagai Pencegahan Banjir," J. Tek. Inform. dan Sist. Inf., vol. 4, pp. 407-421, 2018.

[5] V. Sathya, K. Arun, H. Mahajan, and A. K. Singh, "Automate The Functioning Of Dams Using IoT," 2019 3rd Int. Conf. Comput. Methodol. Commun., no. Iccmc, pp. 1102-1105, 2019.
S. Parjuangan, R. Ali, and A. Purnama, "Real-time monitoring and warning system in urban rivers," TELKOMNIKA, vol. 17, no. 3, pp. $1521-1525,2019$.

[7] X. U. E. Zhang and D. Wang, "An Optimal Regulation Method for Parallel Water-Intake Pump Group of Drinking Water Treatment Process," pp. 82797-82803, 2020.

[8] A. Padlani and T. Informatika, "Pengendali Level Air Tandon Otomatis," PROGRESIF, vol. 14, no. 1, pp. 1-12, 2018.

[9] D. Eka, P. Subekti, F. Teknik, and E. Universitas, "Desain Sistem Pengendali Pintu Air Otomatis Menggunakan Logika Fuzzy Berbasis Ketinggian Permukaan Sungai Dan Komunikasi Frekuensi Radio," in e-Proceeding of Engineering, 2015, vol. 2, no. 3, pp. 7044-7049.

[10] E. Saputra, M. Kabib, and U. M. Kudus, "Rancang Bangun Sistem Kontrol Debit Air Pada Pompa Paralel Berbasis Arduino," CRANKSHAFT, vol. 2, no. Maret 2019, pp. 73-80, 2019.

[11] A. Amin, "Monitoring Water Level Control Berbasis Arduino Uno Menggunakan LCD LM016L," J. EEICT (Electric, Electron. Instrumentation, Control. Telecommun., vol. 1, pp. 41-52, 2018. 